Wawasan:

Jurnal Kediklatan Balai Diklat Keagamaan Jakarta

PISSN: 2548-9232; EISSN: 2775-3573

Volume 2 Nomor 2 Tahun 2021: 100-110

\title{
PENGGUNAAN “LEMKERTAS" DAN YOUTUBE PADA PEMBELAJAR MATEMATIKA JARAK JAUH
}

\author{
Iwan Setiadi \\ Madrasah Aliyah Al Wathoniyah 43 Jakarta, Indonesia \\ E-mail: iwansetiadi43@gmail.com
}

\begin{abstract}
One of the problems with distance learning is the lack of student participation. Teachers must innovate teaching to overcome this participation. This study aims to determine the impact of using LEMKERTAS with the help of YouTube shows on increasing learning activity in math. This study uses a mix method with an explanatory sequential design. The research subjects were 22 students of class XI at MA AL Wathoniyah 43, North Jakarta in the odd semester of 2021/2022. Research instruments in the form of questionnaires, observation sheets, and interviews. The results showed that the use of LEMKERTAS with the help of YouTube shows had an impact on increasing the activeness of learning Mathematics. Students become more active in asking, answering, arguing, discussing, and doing group assignments. Researchers recommend this method to be applied in other subjects.
\end{abstract}

Keywords: active learning mathematics, lemkertas, YouTube, effectiveness, crossword.

\begin{abstract}
Abstrak
Salah satu masalah pada pembelajaran jarak jauh adalah minimnya partisifasi belajar siswa. Untuk mengatasinya guru harus melakukan inovasi. Penelitian ini bertujuan mengetahui dampak penggunaan LEMKERTAS dengan bantuan tayangan YouTube terhadap peningkatan keaktifan belajar Matematika. Penelitian ini menggunakan mix methode dengan rancangan explainatory sequential design. Subjek penelitian sejumlah 22 siswa kelas XI di MA AL Wathoniyah 43 Jakarta Utara pada semester ganjil tahun 2021/2022. Instrumen penelitian berupa angket, lembar observasi, dan wawancara. Hasil penelitian menunjukkan bahwa penggunaan LEMKERTAS dengan bantuan tayangan YouTube berdampak pada peningkatan keaktifan belajar Matematika. Siswa menjadi lebih aktif dalam bertanya, menjawab, berargumentasi, dan berdiskusi dan mengerjakan tugas kelompok. Peneliti merekmendasikan matode ini untuk diterapkan di mata pejaran lainnya.
\end{abstract}

Kata kunci: keaktifan belajar, lemkertas, youtube, teka-teki silang 


\section{PENDAHULUAN}

$\begin{array}{llr}\text { Pandemi } & \text { Covid-19 telah } \\ \text { mempengaruhi } & \text { berbagai sektor } \\ \text { termasuk pada } & \text { sektor pendidikan. }\end{array}$ Sektor ini adalah termasuk salah satu sektor yang paling terdampak. Pemerintah menghentikan sementara proses belajar di sekolah karena pandemi Covid-19. Sesuai dengan SE MENDIKBUD No. 4 tahun 2020 maka proses pembelajaran dilaksanakan dari rumah. Meskipun guru dan siswa benar-benar tidak siap dalam kondisi tidak normal, akan tetapi pembelajaran harus tetap berlangsung. Oleh karena itu, diselenggarakan Pembelajaran Jarak Jauh (PJJ). Pembelajaran Jarak Jauh (PJJ) telah dilaksanakan sesuai dengan SKB empat Menteri RI tahun 2020 mengenai Panduan Penyelenggaraan Pembelajaran di Masa Pandemi Covid19.

Banyak kendala yang ditemukan dalam pelaksanaan PJJ yang dialami oleh peserta didik dan guru (Asmuni, 2020). Beberapa masalah yang dimaksud di antaranya adalah peserta didik kurang aktif dalam pembelajaran, tidak tersedia gawai yang memadai, masalah jaringan internet, kurangnya dukungan dari orang tua, dan keterbatasan guru dalam memantau siswa saat kegiatan PJJ berlangsung.

Matematika, termasuk salah satu mata pelajaran yang memiliki kendala dalam PJJ. Selama pembelajaran dalam jaringan, hasil belajar Matematika pada peserta didik kelas XI-MIA di MAS Al Wathoniyah 43 Jakarta semester genap tahun 2019/2020 hanya 47,62\% siswa yang mencapai kriteria ketuntasan minimal. Guru hanya memberikan tugas kepada siswa yang harus dikerjakan dalam waktu tertentu melalui WhatsApp Group. Tidak ada interaksi langsung dan umpan balik saat itu juga. Umpan balik hanya berupa informasi nilai yang diperoleh siswa pada pertemuan pembelajaran online berikutnya. Guru tidak menggunakan metode ataupun media pembelajaran. Akibatnya, suasana belajar tidak menyenangkan. Siswa banyak yang tidak aktif mengerjakan tugas dari guru, padahal guru senantiasa mengingatkan. Sehingga pembelajaran seperti ini membuat pesera didik tidak minat belajar, malas berpikir dan tidak aktif belajar.

Salah satu kendala utama yang paling urgen adalah rendahnya respon keaktifan belajar dalam PJJ. Ketika PJJ berlangsung menggunakan grup WA Matematika, banyak peserta didik yang hanya mengisi daftar hadir secara online. Saat diskusi dalam grup WA berlangsung, interaksi antara guru dan peserta didik maupun antar peserta didik sangat rendah. Siswa yang bertanya ataupun menjawab pertanyaan dari guru sangat sedikit jumlahnya. Ketika guru memanggil nama siswa di dalam grup, banyak yang tidak merespon. Akhirnya suasana belajar terasa kurang aktif dan kurang menyenangkan.

Dalam kondisi inilah guru harus memiliki kemampuan literasi digital 
agar proses pembelajaran jadi lebih menyenangkan. Guru yang menguasai literasi digital dapat memperkaya kemampuan dan keterampilan mengajar (Wardhana, 2020) sehingga suasana kelas yang menyenangkan membuat siswa aktif belajar (Royani \& Muslim, 2014). Keaktifan belajar adalah keaktifan peserta didik atau tingkah laku peserta didik pada saat proses pembelajaran berlangsung (Afianti et al., 2017). Salah satu hal yang dapat dilakukan untuk membuat suasana belajar aktif dan menyenangkan adalah melalui penggunaan media.

Beberapa penelitian terdahulu sudah dilakukan dan diketahui bahwa untuk dapat meningkatkan keaktifan serta hasil belajar siswa dapat menggunakan media Crossword Puzzle (Setiadi, 2021; Sasriya, Dibia, \& Kusmariyatni, 2016; Puspitasari \& Widiyanto, 2016). Crossword Puzzle merupakan media pembelajaran berbasis permainan.

Pembelajaran Matematika dengan media pembelajaran berbasis permainan memiliki kelebihan dibandingkan pembelajaran biasa (Muhtarom et al., 2016). Siswa tidak merasa jenuh, mendapat umpan balik langsung, aktif, dan suasana belajar Matematika menyenangkan.

\section{Selain media Crossword Puzzle} yang berupa lembar kerja berbasis permainan, media pembelajaran audiovisual pun dapat menarik siswa untuk aktif belajar. Salah satunya adalah tayangan YouTube.
YouTube sudah tidak asing lagi bagi masyarakat saat ini. YouTube dapat digunakan sebagai sumber belajar kaum Milenial (E. F. Setiadi et al., 2019). Selain itu YouTube memiliki potensi dalam pembelajaran matematika (Suwarno, 2017). Hal ini telah dibuktikan dari beberapa hasil penelitian yang menyatakan bahwa YouTube memiliki pengaruh terhdap keaktifan belajar siswa (Astriyani \& Fajriani, 2020; Wulandari et al., 2021) serta efektif dalam pembelajaran dalam jaringan (Wijayanti, 2021).

Berdasarkan kajian pada penelitian-penelitian terdahulu maka peneliti mencoba untuk membuat dan menerapkan suatu media pembelajaran yang menggabungkan antara media Crossword Puzzle dengan tayangan YouTube agar dapat menstimulasi peserta didik lebih aktif belajar Matematika. Peneliti membuat media yang diberi nama LEMKERTAS yang merupakan akronim dari Lembar Kerja Teka-Teki Silang. Media ini berbentuk teka-teki silang yang dibuat menggunakan aplikasi Puzzle Maker.

Selain itu peneliti juga mencoba membuat beberapa video tayangan Youtube sebagai sumber belajarnya. Video-video tersebut digunakan sebagai sumber belajar untuk disimak dan bahan diskusi. Selanjutnya peserta didik diminta untuk bermain quiz berbentuk teka-teki silang (LEMKERTAS) sebagai latihan yang dapat dilakukan berulang-ulang. 
Bahan ajar tersebut merupakan gagasan dan inovasi yang perlu diujicobakan efektifitasnya dalam meningkatkan keaktifan belajar. Untuk kepentingan tersebut peneliti melakukan sebuah penelitian uji pembelajaran. Penelitian tersebut diproyeksikan untuk menjawab rumusan masalah berikut: Bagaimana dampak penggunaan LEMKERTAS dengan bantuan tayangan YouTube terhadap peningkatan keaktifan belajar Matematika? Melalui penelitian ini peneliti ingin menjelaskan dampak media pembelajaran LEMKERTAS dengan bantuan tayangan YouTube terhadap peningkatan keaktifan belajar Matematika. Hasil penelitian dimanfaatkan untuk peneliti sendiri dan guru lain sebagai referensi dalam mencari solusi pada kasus serupa.

\section{METODE}

Penelitian dilaksanakan pada semester ganjil tahun 2021/2022. Adapun tempat pelaksanaan kegiatan secara online di kelas XI MA Al Wathoniyah 43 Jakarta Utara dengan subjek sejumlah 22 orang siswa.

Materi kurikulum yang digunakan adalah materi Matriks pada KD. 3.3, yaitu: menjelaskan matriks dan kesamaan matriks dengan menggunakan masalah kontekstual dan melakukan operasi pada matriks yang meliputi penjumlahan, pengurangan, perkalian skalar, dan perkalian dua matriks serta transpos.
Penelitian ini menggunakan mix method, dengan rancangan explainatory sequential design. Rancangan penelitian kuantitatif menggunakan preexperimental design dalam bentuk one shot-case study (Dantes, 2017). Artinya hanya ada satu kelompok perlakuan. Selanjutnya dilakukan pengambilan data. Data sampel perlakuan selanjutnya dibandingkan dengan skor rerata minimal sebagai kriteria. Sedangkan rancangan penelitian kualitatif menggunakan metode deskriptif.

Instrumen keaktifan belajar siswa menggunakan angket. Angket ini digunakan untuk mengetahui pendapat siswa mengenai keaktifan belajar Matematika menggunakan LEMKERTAS dengan bantuan tayangan YouTube. Angket berisi indikator keaktifan belajar siswa yaitu: mengemukakan pendapat, mengajukan pertanyaan, menjawab pertanyaan dan bekerjasama dalam kelompok untuk pemecahan masalah. Angket dibuat menggunakan google form dan diberikan kepada siswa pada akhir PJJ Matriks. Skor terendah angket adalah 9 sedangkan skor tertinggi 45. Hasil angket ini kemudian dianalisis secara kuantitatif. Sedangkan lembar observasi, pedoman wawancara, dan tangkapan layar gawai digunakan sebagai instrumen untuk mendeskripsikan dampak penggunaan LEMKERTAS dengan bantuan tayangan YouTube terhadap keaktifan 
belajar siswa selama proses pembelajaran berlangsung.

Kriteria keaktifan belajar siswa seperti tampak pada Tabel 1 (Mardapi, 2012).

Tabel 1. Kriteria Keaktifan Belajar Siswa

\begin{tabular}{rcc}
\hline No & Skor Interval & Kategori \\
\hline 1 & $36-45$ & Sangat Tinggi \\
\hline 2 & $27-35$ & Tinggi \\
\hline 3 & $18-26$ & Rendah \\
\hline 4 & $9-25$ & Sangat Rendah \\
\hline
\end{tabular}

Selanjutnya peneliti mengambil batas skor rerata minimal sebagai kriteria untuk keperluan analisis data, yaitu sebesar 27 dalam Tabel 1. Dengan nilai ini maka masuk pada kategori tinggi.

Data hasil angket dianalisis menggunakan uji-t dengan rumus (Dantes, 2017):

$$
t=\frac{\bar{x}-\mu}{\sqrt{\frac{\sum D^{2}}{N\left(N^{2}-1\right)}}}
$$

Keterangan:

$$
\begin{aligned}
\bar{x} & =\text { rerata keseluruhan data } \\
\mu & =\text { rerata yang ditetapkan } \\
D & =\bar{x}-\mu \\
N & =\text { jumlah seluruh data }
\end{aligned}
$$

Berdasarkan rumus uji-t tersebut maka, data yang dianalisis adalah perbandingan antara rata-rata keseluruhan hasil angket $(\bar{x})$ dengan rata-rata skor angket yang ditetapkan sebagai kriteria keaktifan belajar siswa di batas skor rerata minimal pada kategori tinggi $(\mu)$.
Selanjutnya untuk melihat tingkat efektivitas/Efektivitas size (ES) menggunakan rumus (Dantes, 2017):

$$
E S=t \sqrt{\frac{1}{N}}
$$

Keterangan:

$$
\begin{aligned}
t & =\text { hasil } t_{\text {hitung }} \\
N & =\text { jumlah seluruh data }
\end{aligned}
$$

\section{HASIL DAN PEMBAHASAN \\ Tahap Perencanaan}

LEMKERTAS atau Lembar Kerja Teka-Teki Silang dibuat oleh guru dengan bantuan aplikasi Puzzle Maker. Tiap LEMKERTAS berisi soal-soal Matriks, sesuai dengan indikator pencapaian kompetensi yang dibuat oleh guru. Adapun Langkah-langkah pembuatannya sebagai berikut: 1) Menuliskan JAWABAN dan SOAL materi Matriks pada MS Word; 2) Membuka aplikasi Puzzle Maker di mesin pencari Google; 3) Pilih menu Criss-Cross pada Puzzle Maker; 4) Masukan Judul Pada kotak bertuliskan Step 1;5) Menyalin JAWABAN dan SOAL matriks yang telah dibuat pada MS Word ke kotak Step 2; 6) Tekan Create My Puzzle pada step 3. 7) Terakhir, tekan Copy Puzzle untuk menyalin TTS ke MS Word sebagai lembar kerja siswa.

Selanjutnya guru membuat Materi pada tayangan Youtube. Materi disesuaikan dengan LEMKERTAS yang telah dibuat.

\section{Tahap Pelaksanaan}

Penelitian dilaksanakan sesuai dengan rencana pelaksanaan pembelajaran jarak jauh yang telah 
dibuat oleh guru. Jumlah jam pelajaran sebanyak 16 jp atau empat kali pertemuan. Rinciannya adalah tiga pertemuan menggunakan LEMKERTAS dengan bantuan tayangan YouTube dan satu pertemuan untuk penilaian hasil belajar serta mengisi angket. Selama tiga pertemuan tersebut Guru mengamati keaktifan siswa sesuai dengan indikator. Proses PJJ dilaksanakan dalam jaringan synchronous menggunakan WAGM.

Pada proses pelaksanaan pembelajaran, guru lakukan dengan tahapan: pertemuan pertama, siswa menggunakan media LEMKERTAS dengan sub materi pengertian matriks, menentukan ordo suatu matriks, menentukan transpose suatu matriks, dam menentukan jenis-jenis matriks. Siswa berdiskusi di dalam masingmasing kelompok melalui kelompok WAG diskusi. Guru ada di dalam setiap kelompok WAG diskusi untuk memberikan umpan balik langsung sekaligus mengobservasi keaktifan belajar siswa. Setelah diskusi kelompok selesai, Dilanjutkan diskusi dalam WAGM. Perwakilan setiap kelompok mempresentasikan hasil diskusinya. Kemudian diakhiri dengan refleksi siswa dan guru pada proses pembelajaran saat itu. Pertemuan kedua, sampai ketiga semua tahapannya sama. Hanya sub materinya yang berbeda.

\section{Tahap Pelaksanaan Pembelajaran}

Pembelajaran pertama dilakukan pada tanggal 1 September 2021. Siswa mendiskusikan penyelesaian LEMKERTAS 1 yang berisi permasalahan mengenai pengertian matriks, menentukan ordo suatu matriks, menentukan transpose suatu matriks, dan menentukan jenis-jenis matriks. Sedangkan pada pembelajaran kedua dilaksanakan pada tanggal 8 September 2021. Siswa mendiskusikan permasalahan operasi pada matriks dan kesamaan matriks. Pada pertemuan ketiga tanggal 15 September 2021, siswa mendiskusikan bagaimana caranya melakukan perkalian dua buah matriks.

Di setiap awal pertemuan, siswa secara individu terlebih dahulu mengamati tayangan YouTube yang sudah dibuat oleh guru dan disesuaikan dengan LEMKERTAS. Siswa diberikan waktu tertentu untuk mempelajari materi dari tayangan tersebut.

Selama tahap ini, guru mengamati jalannya diskusi kelompok. Pada awal pembelajaran, guru membagi kelompok secara heterogen dari segi kemampuan siswa. Satu kelompok terdiri dari empat sampai lima orang siswa. Selanjutnya guru meminta siswa untuk membuat kelompok diskusi pada WA group dan guru ada di dalamnya. Guru mengamati dan mencatat respon siswa selama diskusi sesuai dengan indikator keaktifan belajar siswa.

\section{Tahap Akhir Pembelajaran}

Pembelajaran Matematika pada materi Matriks menggunakan LEMKERTAS dengan bantuan tayangan YouTube, diakhiri dengan presentasi di setiap pertemuan. Masing-masing perwakilan siswa 
Wawasan:

Jurnal Kediklatan Balai Diklat Keagamaan Jakarta PISSN: 2548-9232; EISSN: 2775-3573

Volume 2 Nomor 2 Tahun 2021: 100-110

mempresentasikan jawaban kelompok. Siswa tampak antusias menjawab dan saling berlomba untuk menjawab paling dahulu. Guru langsung memberikan penilaian dan umpan balik saat itu juga. Selanjutnya guru meminta siswa untuk mengumpulkan jawaban kelompok melalui email guru.

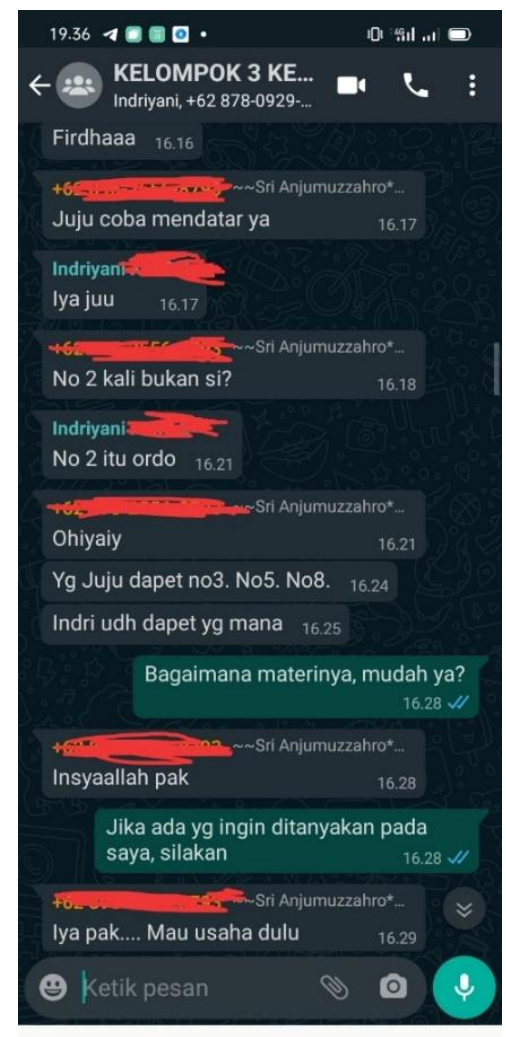

Gambar 1 Contoh Diskusi Siswa dalam Kelompok.

Gambar 1 adalah salah satu contoh diskusi siswa dalam kelompok. Terlihat dari percakapan bagaimana siswa berdiskusi menyelesaikan tugas kelompok.

Pada pertemuan keempat, yaitu tanggal 22 September 2021, siswa secara individu mengerjakan soal kuis dan mengisi angket. Tujuan kuis adalah untuk mengetahui pemahaman siswa sedangkan angket untuk mengetahui sikap siswa dalam mempelajari materi Matriks menggunakan LEMKERTAS dengan tayangan YouTube.

\section{Keaktifan Belajar}

Keaktifan pembelajaran Matematika, dapat diketahui melalui angket, observasi dan wawancara. Data yang diperoleh melalui angket dapat dijelaskan sebagai berikut.

Pada pernyataan bahwa pembelajaran Matriks menggunakan LEMKERTAS membuat saya aktif belajar matematika, sebanyak $81,8 \%$ siswa menyetujui pernyataan ini. 9,1\% menyatakan sangat setuju. Artinya sebagian besar siswa mengakui bahwa LEMKERTAS dapat membuat siswa aktif belajar matriks. Hal inipun dapat dilihat dari rerata skala yang diperoleh sebesar 3,95. Hasil penelitian ini sesuai dengan penelitian Puspitasari \& Widiyanto, (2016) yang menyimpulkan bahwa penggunaan Teka-Teki Silang dapat meningkatkan keaktifan belajar siswa.

Pernyataan bahwa pembelajaran matriks menggunakan LEMKERTAS membuat saya aktif bertanya ketika diskusi kelompok, memiliki tingkat persetujuan siswa sebesar $72,7 \%$ dan sangat setuju $4,5 \%$. Siswa mengakui bahwa LEMKERTAS membuat dirinya aktif bertanya dalam diskusi kelompok. Data ini diperkuat dari rerata skala sebesar 3,82 .

Untuk pernyataan pembelajaran matriks menggunakan LEMKERTAS 
membuat saya aktif menjawab ketika diskusi kelompok memiliki rerata skala 3,86. Ini juga menunjukkan bahwa tingkat persetujuan siswa sebagian besar mengakui bahwa LEMKERTAS membuat siswa aktif menjawab ketika diskusi kelompok.

Adapun mengenai pernyataan Pembelajaran matriks menggunakan LEMKERTAS membuat saya aktif mengemukakan pendapat ketika diskusi kelompok memiliki rerata skala 3,77. Artinya tingkat persetujuan pernyataan ini tinggi, yaitu sejumlah $77,3 \%$ siswa setuju.

Pernyataan pembelajaran matriks menggunakan LEMKERTAS membuat saya aktif bekerja sama dalam kelompok diskusi juga memperoleh tingkat persetujuan yang tinggi. Sejumlah $72,7 \%$ siswa setuju dan 9,1\% siswa menyatakan sangat setuju. Adapula siswa yang menyatakan tidak setuju sebesar 4,5\%. Rerata skala ini adalah 3,86 .

Seorang siswa tidak setuju pada pernyataan ini dengan alasan sebagai berikut: "Karena mengerjakan lembar kerja kelompok ada positif dan negatif Pak. Positif nya sih buat saya aktif, tapi terkadang dalam kelompok kurang kerjasamanya Pak. Ada yang membantu ada yang tidak" (Wawancara siswa, 25 September 2021). Komentar siswa tersebut menunjukkan bahwa siswa merasa keberatan apabila dalam tugas diskusi kelompok terdapat siswa yang tidak ikut berpartisipasi untuk terlibat dalam menyelesaikan masalah.
Hal mengenai pernyataan pembelajaran matriks menggunakan media You Tube membantu saya memahami materi matriks memiliki tingkat persetujuan $68,2 \%$ dan sangat setuju 9,1\%. Tetapi sejumlah 4,5\% siswa tidak setuju atas pernyataan ini. Namun demikian masih menunjukkan bahwa pernyataan ini sebagian besar menyetujui dengan rerata skala 3,82. Seorang siswa memiliki pendapat yang berbeda dan tidak menyetujui pernyataan ini. Hal ini diungkapkan siswa sebagai berikut. "...terkadang saya lebih suka zoom atau bahas langsung Pak. Bisa nanya soal yang sulit, terkadang kalau di Vidio yt hanya contoh yang dasar nya ajah Pak" (Wawancara siswa, 25 September 2021).

Berdasarkan komentar siswa tersebut maka siswa menginginkan contoh atau penjelasan materi yang lebih beragam dari tayangan YouTube tersebut. Bukan hanya contoh dasar melainkan contoh soal yang lebih kompleks.

Pernyataan bahwa pembelajaran matriks menggunakan media You Tube membantu saya menjawab soal-soal matriks pada LEMKERTAS memiliki tingkat persetujuan yang agak menurun, yaitu $54,5 \%$. Siswa yang sangat setuju sebesar $13,6 \%$. Walaupun demikian masih menujukkan bahwa Sebagian besar siswa menyetuji pernyataan ini. Hal ini juga didukung oleh rerata skala sebesar 3,82 .

Dalam hal pernyataan pembelajaran matriks menggunakan media You Tube dan 
LEMKERTAS membuat saya senang belajar Matriks menujukkan penurunan. Siswa yang setuju dengan pernyataan ini sebesar $63,6 \%$ dengan rerata skala sebesar 3,73. Tetapi hal ini masih menunjukkan Sebagian besar siswa setuju atas pernyataan ini.

Pernyataan pembelajaran matriks menggunakan media YouTube dan LEMKERTAS membuat saya aktif belajar Matriks memiliki tingkat persetujuan $68,2 \%$ dan sangat setuju 9,1\%. Adapun rerata skala 3,86. Hal ini artinya bahwa siswa mengakui pembelajaran Matematika pada materi Matriks dengan bantuan YouTube pada sebagian besar siswa membuat aktif belajar.

\section{Hasil Uji Analisis Data}

Berdasarkan data angket yang diperoleh, maka sebaran data angket dapat diperlihatkan sebagaimana tampak pada Gambar 2.

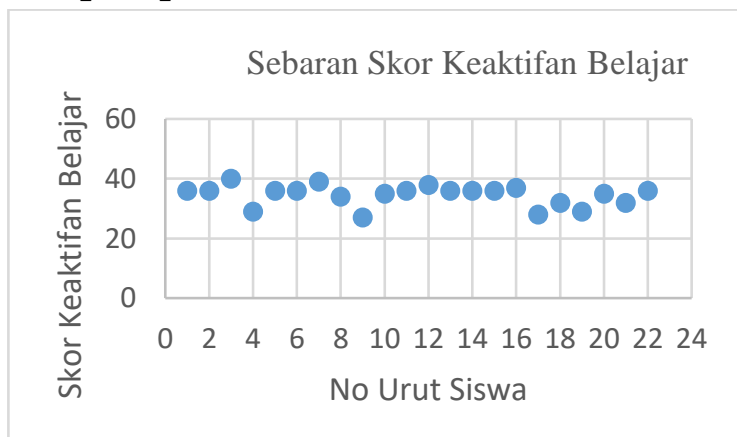

Gambar 2 Sebaran Skor Keaktifan Belajar

Berdasarkan data tersebut diketahui bahwa skor tertinggi 40 dan skor terendah 27 . Sedangkan nilai rerata skor adalah 34,50 dengan simpangan baku 3,53.
Hasil analisis data perbedaan ratarata keseluruhan hasil angket dengan rata-rata skor angket yang ditetapkan sebagai kriteria keaktifan belajar siswa menggunakan uji-t diperoleh $t_{h i t}=$ 19,97. Sedangkan $t_{\text {tabel }}=2,08$ pada taraf signifikansi $\alpha=0,05$ dan $d k=21$. Hal ini berarti $t_{\text {hit }}>t_{\text {tabel }}$. Artinya secara signifikan terdapat perbedaan rata-rata hasil angket keaktifan belajar siswa dengan rata-rata skor angket kriteria keaktifan belajar. Dengan kata lain terdapat dampak penggunaan LEMKERTAS dengan bantuan tayangan YouTube terhadap keaktifan pebelajar Matematika jarak jauh. Sedangkan efektivitas size (ES) diperoleh $=0,91$. Nilai ES ini tergolong tinggi (Dantes, 2017). Berdasarkan nilai ES yang diperoleh maka dengan demikian penggunaan LEMKERTAS dengan bantuan tayangan YouTube memiliki efektifitas yang tinggi terhadap keaktifan belajar siswa.

Hasil penelitian ini menunjukkan bahwa penerapan dua media pembelajaran memberikan dampak yang signifikan terhadap keaktifan belajar siswa. Penggunaan tayangan YouTube sebagai media audio visual efektif dalam mendorong siswa untuk belajar aktif. Oleh karena itu agar hasil tayangan bukan hanya tontonan semata maka penggunaan LEMKERTAS menjadi pelengkap siswa agar dapat belajar aktif. Hasil penelitian ini sejalan dengan hasil penelitian Astriyani \& Fajriani, (2020) yang menjelaskan bahwa Penggunaan Media Audio Visual Youtube memiliki pengaruh terhadap keaktifan belajar Matematika siswa. 


\section{KESIMPULAN}

Berdasarkan hasil penelitian maka dapat disimpulkan bahwa dampak penggunaan LEMKERTAS dengan bantuan tayangan YouTube adalah keaktifan siswa belajar Matematika mengalami peningkatan. Peningkatan keaktifan belajar terjadi pada semua aspek. Siswa menjadi lebih aktif dalam bertanya, menjawab, berargumentasi, dan berdiskusi mengerjakan tugas kelompok. Hal ini diperkuat dengan hasil analisis data menggunakan uji-t yang menyatakan bahwa secara signifikan terdapat perbedaan rerata skor keaktifan belajar. Selain itu, tingkat efektivitas penggunaan LEMKERTAS dengan bantuan tayangan YouTube tergolong tinggi pada peningkatan keaktifan belajar Matematika.

Implikasi dalam penelitiaan ini adalah siswa menjadi lebih berani dalam bertanya, menjawab, dan berargumentasi dalam diskusi kelompok melalui WA group. Siswa memiliki rasa percaya diri untuk menjawab soal-soal Matriks melalui LEMKERTAS yang menyerupai TTS.

Berdasarkan hasil penelitian dan pembahasan maka disarankan sebagai berikut: 1) Gunakan materi lain selain materi Matriks. 2) Buatlah konten materi dengan contoh soal yang lebih kompleks.

\section{DAFTAR PUSTAKA}

Afianti, N. W., Sulastry, T., \& Alimin, A. (2017). Penerapan Model Pembelajaran Kooperatif Tipe Kancing Gemerincing untuk Meningkatkan Keaktifan dan Hasil Belajar Peserta Didik Kelas X MIA 3 SMAN 1 Bontomarannu. Jurnal Nalar Pendidikan, 5(2), 544-551. https://doi.org/10.26858/jnp.v5i2.4869.

Astriyani, A., \& Fajriani, F. (2020). PENGARUH PENGGUNAAN MEDIA AUDIO VISUAL YOUTUBE MATERI PYTHAGORAS TERHADAP KEAKTIFAN BELAJAR MATEMATIKA SISWA. FIBONACCI: Jurnal Pendidikan Matematika Dan Matematika, 6(1), 87-90. https:/ / doi.org/10.24853/fbc.6.1.87-90.

Muhtarom, Nizaruddin, \& Sugiyanti. (2016). Pengembangan Permainan Teka-Teki Silang dalam Pembelajaran Matematika di Kelas VII SMP. PYTHAGORAS, 5(April), 20-31. https:// doi.org/10.33373/pythagoras.v5i1.235.

Puspitasari, C., \& Widiyanto, J. (2016). Upaya Meningkatkan Keaktifan dan Prestasi

Belajar Menggunakan Media Teka-Teki Silang dengan Model Pembelajaran Talking Stick Pokok Bahasan Ekosistem Kelas VII SMPN 1 Kartoharjo. Jurnal Florea, 3(1), 3945. https:/ / doi.org/10.25273/florea.v3i1.786.

Royani, M., \& Muslim, B. (2014). Keterampilan Bertanya Siswa SMP Melalui Strategi Pembelajaran Aktif Tipe Team Quiz Pada Materi Segi Empat. EDU-MAT: Jurnal Pendidikan Matematika, 2(1), 22-28. https:/ / doi.org/10.20527/edumat.v2i1.586.

Sasriya, T., Dibia, I. K., \& Kusmariyatni, N. (2016). Penerapan Model Pembelajaran NHT Berbantuan Media Teka-Teki Silang untuk Meningkatkan Keaktifan dan Hasi 
Belajar. Mimbar PGSD UNDIKSHA, 6(3), 1-9. https://doi.org/10.25273/jipm.v3i2.514.

Setiadi, E. F., Azmi, A., \& Indrawadi, J. (2019). Youtube Sebagai Sumber Belajar Generasi Milenial. Journal of Civic Education, 2(3), 313-323. https://doi.org/10.24036/jce.v2i4.135.

Setiadi, I. (2021). Peningkatan Keaktifan dan Kemandirian Belajar Matematika Siswa dalam Jaringan Synchronous Menggunakan Media Crossword Puzzle. Suska Journal of Mathematics Education, 7(1), 1-12. https:// doi.org/10.24014/sjme.v7i1.11938.

Suwarno, M. (2017). Potensi YouTube Sebagai Sumber Belajar Matematika. Pi: Mathematics Education Journal, 1(1), 1-7. https:/ / doi.org/10.21067/ pmej.v1i1.1989.

Wardhana, W. S. (2020). Strategi Pengembangan Kompetensi Guru Secara Mandiri di Era Literasi Digital. Prosiding Seminar Nasional Bahasa Dan Sastra Indonesia (SENASBASA), 4(1), 424-431.

Wijayanti, A. (2021). EFEKTIVITAS PEMBELAJARAN DARING BERBANTUAN YOUTUBE DENGAN MODEL PEER TEACHING TERHADAP PRESTASI BELAJAR MATEMATIKA SISWA. ALGORITMA: Journal of Mathematics Education, 3(1), 41-57. https://doi.org/10.15408/ajme.v3i1.20228.

Wulandari, A. R., Masturi, M., \& Fakhriyah, F. (2021). Pengaruh media pembelajaran berbasis youtube terhadap hasil belajar IPA siswa di sekolah dasar. Edukatif: Jurnal Ilmu Pendidikan, 3(6), 3779-3785. https:/ / doi.org/10.31004/edukatif.v3i6.1251. 